\title{
Ethics of the Dialectic Dichotomy in Physician-Patient Relationships
}

\author{
Masud KHAWAJA ${ }^{a}$
}

\begin{abstract}
Communication is the cornerstone of the physician-patient relationship. However, a difference in medical knowledge may create a communicative gap, negatively affecting the patient experience. Rather than bridging the difference in knowledge, physicians who overutilize technical medical language can further damage the relationship. To prevent this, Voice can be analyzed through an ethical lens as it relates to patient autonomy and patient understanding, as comprehension is required for the patient to give informed consent. Research suggests that improved communication and empathy radically increases patient satisfaction. This end is achieved by incorporating not only the Voice of Medicine but also the Voice of the Lifeworld. The former employs scientific jargon and technical-speak while the latter incorporates the patient's lived experiences into the medical dialogue. The Voice of the Lifeworld is a valuable tool that contextualizes disease and dissolves communication barriers. Physicians must appreciate patient perspectives to establish trust and pursue meaningful relationships. The use of either Voice is situation-specific and should be balanced according to the patient's context; failure to do so will result in patient dissatisfaction. With this framework as a foundation, physicians can further optimize interactions with their patients by matching Voice not only to the medical context, but further extending Voice into a more personal context. Attachment theory provides a second lens that predicts how one may respond to medical professionals attempting to build trusting relationships. Depending on the attachment style, patients may be easier to comfort and build rapport with. Altering the communication mix according to Voice and attachment style will offer a truly personalized healthcare experience to each patient. Future studies should test this framework and attempt to determine attachment style quickly and methodically, so trust can be built early in the relationship. The outcome of this proposed process suggests that revised medical training be implemented to satisfy patients' Lifeworld Voice and to increase clarity within the physician-patient relationship to promote ethical communication.
\end{abstract}

Keywords: Patient autonomy; beneficence; paternalism; health communication; attachment theory

\section{BACKGROUND}

Anatole Broyard (1), Professor at Columbia University, wrote the following about his physician shortly before passing away due to prostate cancer: "I just wish he would brood on my situation for perhaps five minutes, that he would give me his whole mind just once, be bonded with me for a brief space, survey my soul as well as my flesh to get at my illness."

The failure of contemporary medical practice to meet patients' needs and expectations is well documented in academic literature (2). One reason for this shortcoming is observable during the typical medical interview process, where poor communication has been attributed to widespread patient dissatisfaction (3). This is cause for concern as dissatisfaction among patients can lead to serious problems such as noncompliance, medical complications, and litigation (4). In addition, this has serious ethical implications, and physicians must be aware of this possible shortcoming to give patients the best possible treatment. Doing everything possible to meet patients' expectations is more important than ever during the COVID-19 pandemic, where medical ethics must be followed, and patient needs must be prioritized. Currently, medical interviewing techniques lack a common focus which may be contributing to patient complaints (5). This critical process deserves uniformity and refinement

${ }^{a}$ University of the Fraser Valley, Abbotsford, Canada, $\bowtie$ masud.khawaja@ufv.ca

Gönderim Tarihi: 10.05.2021 • Kabul Tarihi: 11.07.2021 
to maximize patient benefits. The need to improve communicative skills should be considered paramount. Communication is among the most important soft skills for a physician to possess, as prowess in this area will result in the most effective interview, leaving the patient better informed (6-7).

While extremely useful to medical practice overall, medical technology is one such barrier to interpersonal interactions between physician and patient. Over thirty years ago, Flaherty (8) observed that, with advancement in medical technology, the basic tools of Western medicine such as history-taking and physical examination were becoming neglected in medical practice. Today, this notion seems to have become more widespread. Stewart et al. (9) contend that patients become noticeably resentful when medical technology overtakes the agenda. Technology-centered treatment minimizes the importance of patients' unique personal stories. This is significant, as the patient may leave the appointment feeling that they were unheard or rushed during the medical visit. Because of this, patients may experience feelings of isolation, anxiety, or fear. Patients may also question whether their concerns were thoroughly examined by the physician. From an ethical perspective, a patient may not be given full autonomy over their treatment if physicians ignore the personal narrative and choose a treatment path based solely on technological information. Although medical technology has developed healthcare exponentially (10), the basic premise of physician-patient interactions remains the same: to provide care that is unique to the patient.

The potential barrier caused by medical technology is an example of the communicative gaps that arise in the physician-patient relationship, signaling a need for improvement of medical discussions, to allow for better patient understanding. Patients are unique in their communication styles and abilities, which requires the physician to make adaptations for the best medical experience. Understanding how communication takes place will aid in developing new models that ease discourse. The degree to which elements of medicine dominate a conversation will either inhibit or expedite information transmission, depending on the patient's level of understanding. Similarly, a patient's precise style of attachment may also affect information uptake, as this action may be tempered by one's ability to form trusting relationships. By blending these perspectives, it may be possible to codify a new model of communication that delivers quick dissemination that is fully understood by the patient. Ideally, communication should be developed in such a way that it removes patients' doubts, clarifies the course of treatment, and dissipates the power differences present in paternalistic relationships. If achieved, this style of communication in physicianpatient relationships will lead to much more ethical encounters amongst this dyad.

\section{VOICE AFFECTS ETHICS OF MEDICINE}

Mishler's (11) theoretical concept of two contrasting dialectic frameworks characterizes physician-patient communication. This concept is useful when analyzing issues that occur during medical interviews. Mishler explains two voices of medical dialogue: Voice of Medicine and Voice of the Lifeworld. In a typical interview setting, the physician and the patient talk to each other with different voices. The Voice of Medicine represents the technical and scientific assumptions of medicine, while the Voice of the Lifeworld represents the natural attitude of everyday life (11). However, there is tension between these two voices, and they often come into conflict (12). Voice usage can be understood when analyzing the encounter using an ethical lens. When the dynamics of Voice use are evaluated during a medical encounter, Voices give insight into how much control patients are given over their treatment. Voices also help to establish a line of communication for physicianpatient relationships, which ultimately encourages honesty and rapport.

The Voice of Medicine is characterized by medical terminology, objective descriptions of physical symptoms, and the classification of symptoms within a biomedical model (13). In a standard medical interview of the prevailing model, the Voice of Medicine dominates. Hegemonic power enjoyed by the physician may result in the patient's voice being suppressed (14). The physician tends to control the content and form of the interview by unilaterally defining what is relevant and irrelevant through the questions asked. Distorted 
medical communication often occurs when a physician delivers a technical diagnosis employing the Voice of Medicine, as it is incompatible with the less technical Voice of the Lifeworld used by the patient (15). Delivering information that is not understood by the patient betrays traditional medical ethics, requiring that patients be informed of and give consent to medical treatment. Moreover, medical jargon should not be relied on when assessing patients in a medical interview setting. Mishler (11) asserts that the Voice of Medicine manifests a scientific attitude in which the "meanings of events are provided through abstract rules that serve to decontextualize events, to remove them from particular personal and social contexts" (p.104).

Many commentators have responded to Mishler's framework. According to Stewart (9), the Voice of Medicine asks questions such as "When did it start? Where does it hurt? How long does it last? What makes it better or worse?" (p.36). Contrasting this dialect, the Voice of the Lifeworld relates directly to patients' lived experiences. Patients' Voice is therefore characterized by non-technical discourse related to the subjective experience of illness within the context of everyday life and social relationships. Typical questions that explore the Lifeworld include: 'What are you most concerned about? How does it disrupt your life? What do you think it is? How do you think I can help you?' (9). The two voices conflict in some ways, as the Lifeworld perspective perceives illness as having many causes based on daily life, while the technical medical perspective seeks the one correct biomedical answer (12). Mishler observes that most physicians tend to consider the Voice of the Lifeworld as irrelevant and medically insignificant. Due to physician's convoluted attitudes towards the Voice of the Lifeworld, relationships between physicians and patients will continuously be indifferent until this voice is recognized. Nilsson et al. (13) emphasize that the Voice of the Lifeworld must be heard. Patients are not objective observers who can report on their diseases mechanically. They narrate what has happened to them and assign meaning, interpretations, and causal explanations to their narration. When the physician attends to the Voice of the Lifeworld, the contextual narration of the patient's story is facilitated.

Kirkscey et al. (17) preface that empathy is a pivotal component of physician-patient relationships. It is also suggested that the Voice of the Lifeworld must be established before the Voice of Medicine; interpersonal communication and trust should be the cornerstone of the medical relationship. While physicians may guide patients through many phases of life, there is no time more critical to communicate such empathy than in that of dying. When the end-of-life approaches, the physician is seen as the first point of hope and support (18). The conveyance of empathy and trust is important, not only to the patient but also to the patient's family. Allowing patients and the next of kin knowledge and control over medical treatment at the end of life is crucial in respecting human dignity and upholding the ethics of medicine. In this scenario and others, The Voice of Medicine and the Voice of the Lifeworld must intertwine harmoniously to obtain an accurate diagnosis, increase patient satisfaction, and demonstrate empathy.

Silverman (19) echoes the need for plurality by critiquing the distinctive classification of the two voices. According to him, it is a faulty assumption that physicians primarily speak in the Medical Voice and that patients always speak in the Lifeworld Voice. Additionally, he rejects the notion that, if both speak in the same Lifeworld voice, more liberating and effective communication will occur. Silverman contends that both the physician and patient should blend the Voice of Medicine and that of the Lifeworld in a manner that is contextually suitable. Medical communication, as taught in medical school, functions to construct a professional identity for physicians, which is grounded in the principles of the biomedical model (20). However, in instances where the Voice of the Lifeworld is used, socially rich interactions can occur. The physician must be willing to integrate the two Voices, share power, display empathy, and listen to what the patient has to say. With the power differential minimized, a more meaningful dialogue can take place, resulting in a comparatively more effective encounter. In any case, ample patient understanding must be prioritized to ensure that the ethics of medicine are being met, and that informed consent can be given. 


\section{USING VOICE TO INCREASE COMMUNICATION \& PATIENT AUTONOMY}

Barry et al. (21) categorized the Voices into four types, extending Mishler's initial concept. The labels for the voice patterns that were used in their study are Strictly Medicine, Mutual Lifeworld, Lifeworld Blocked, and Lifeworld Ignored (Figure 1).

Figure 1: Voice Categories Highlighting Ethical Communication and Patient Satisfaction

\section{Strictly Medicine}

-Both Dr. \& Pt. Use Medicine

- Satisfied patienta

-Effective interview

-Appropriate for uncomplicated medical issues

Mutual Lifeworld

- Both Dr. \& Pt. Use Lifeworld

-Satisfied patient

-Effective interview

-Appropriate for complicated medical issues

Lifeworld Blocked or Ignored

-Dr. Uses Medicine, Pt. Uses Lifeworld

-Dissatisfied patient

- Ineffective interview

- Never appropriate

Unlikely Scenario

-Pt. Uses Medicine, Dr. Uses Lifeworld

-Unknown satisfaction

-Unknown effectiveness

-Unknown appropriateness

In the case of Strictly Medicine, both the physician and patient speak entirely in the Voice of Medicine. In Lifeworld Blocked, there are brief moments of natural everyday interactions, but they are quickly suppressed by the physician's closed-ended mode of structured inquiry. In the Lifeworld Ignored group, the patient speaks in the Voice of the Lifeworld, which is completely ignored by the physician who conducts the entire consultation in the Voice of Medicine. In the Mutual Lifeworld group, both the physician and the patient use the Voice of the Lifeworld throughout their consultation. Furthermore, hypothetically where the patient may speak in the Voice of Medicine while the physician instead chooses to speak in the Voice of the Lifeworld, the outcomes and situation-appropriateness of this pattern remain unknown, since it is a very unlikely scenario. One method to improve physician-patient communication is to understand the context of the medical issue and match Voices accordingly. Situations where the physician does not allow patients to speak in their Lifeworld 
dialect infringes upon their rights to autonomy, from an ethical perspective. Moreover, ample efforts and clarification must be made for patients to feel respected and heard in medical interviews.

According to the Barry et al. (21) study, the categories of Lifeworld Blocked and Lifeworld Ignored had the poorest outcomes in terms of patient satisfaction and interview effectiveness. However, Mutual Lifeworld and Strictly Medicine did equally well, which was a surprise to the researchers. Upon further analysis, it was revealed that the sample for Strictly Medicine cases in the study was comprised of patients with relatively straightforward medical issues, such as tonsillitis and ear infections. Most of the cases in the Mutual Lifeworld group had more complex health issues with patients presenting multiple problems and complications. Thus, it was evident that the Mutual Lifeworld approach worked best for patients with complicated issues. Patients with more routine, less serious illnesses could however benefit from a traditional biomedical approach to physician-patient communication.

\section{USING ATTACHMENT THEORY TO EMPHASIZE PATIENT HUMANITY}

Recent studies by sociologists and psychologists linking the construct of attachment theory to physicianpatient relationships provide a second relevant ethical lens to assess medical interviews (22). Bowlby (23) is considered the father of attachment theory, but some scholars give credit to both Ainsworth and Bowlby (24) for postulating the theory. According to them, attachment is said to result when a more vulnerable member bonds with a stronger or wiser person. Attachment may be defined as an emotional connection between two persons in which it is expected that one or both individuals will provide protection and care in times of need (25). Understanding how patients form attachments will help overcome communicative barriers and improve medical outcomes.

Once formed, attachment undergirds all interactions. However, research has shown that attachment behavior becomes especially activated during stressful situations (26). A medical encounter can be one such instance, depending on the nature of the encounter. As previously discussed, end of life is especially distressing for patients and their loved ones. Thus, this is a stage where attachment would be activated. Differences in styles of attachment affect the extent to which one can be soothed by healthcare providers in stressful moments (27).

Several studies show that there exists a direct correlation between attachment styles and helping relationships, such as those in a healthcare setting (28). Based on empirical evidence, Griffin and Bartholomew (29) have identified four styles of attachment in adults: secure, preoccupied, dismissing, and, fearful. When constructing a new framework of medical interview communication, it will be useful to categorize individuals in terms of their predominant attachment style. This will allow physicians to further explore and understand a patient's overall health (30). For instance, those with a secure attachment style experience responsive caregiving (31) and are more easily comforted by others. These individuals are more satisfied with medical care in general than those with less secure attachment styles (32). Secure type individuals typically value close relationships (33). Armed with this knowledge, physicians may be better able to connect with this type of patient during medical interviews, but further studies must be conducted to support this hypothesis.

Less secure attachment styles, on the other hand, experience early caregiving that ranges from emotionally rejecting to inconsistent (34-35). These individuals are more challenging to connect with during medical interviews. Dismissive style individuals, for instance, may have a positive view of themselves but are uncomfortable trusting others (23). They are also least likely to seek psychotherapeutic support (36). Preoccupied style individuals have a positive model of others and exaggerate behaviors to attract their support (36). Such individuals present themselves as vulnerable and have high expectations of being taken care of (37). Fearful individuals are the most difficult to connect with due to a rejecting upbringing. Although desiring intimacy, they tend to avoid close relationships due to the fear of rejection (38). Such an attachment style can lead to potential problems 
with treatment compliance. Studies have shown that psychiatric patients with a fearful attachment style have a higher risk for suicidal behavior; the opposite was found to be true for secure attachment individuals (39). In line with the medical ethics principle of beneficence, physicians must do everything they can to improve the well-being of the patient. Understanding barriers to effective communication, such as insecure attachment, can allow physicians to overcome obstacles and thus achieve improved patient outcomes.

Comprehending and appreciating attachment theory allows for a more patient-centric understanding of the physician-patient relationship, which can ultimately result in the more ethical treatment of patients. While most theoretical concepts related to the relationship help explain the overall interactive process, attachment theory portends to establish a sound approach to understanding this relationship at the individual level. More than any other construct, attachment theory helps us appreciate the need for a 'good fit' in medical interactions. This successfully brings us one step closer to truly customizable care in medical practices, with patient dignity being the top priority. Some analysts have even suggested that emphasizing a focus on human dignity is the defining difference between human medicine and veterinary medicine (40). Thus, respect and utilization of available methods to enhance patient care are of utmost importance to demonstrate an appreciation of patient humanity.

\section{USING VOICE AND ATTACHMENT THEORY TO PROMOTE BENEFICENCE}

Understanding the concept of dialectic Voice along with attachment theory provides physicians with two powerful tools to remove communicative barriers with patients. Further gains stand to be realized when the two constructs are combined. Improving patient outcomes is in alignment with the medical ethic of beneficence. With a thorough understanding of the Voice categories and attachment theory, we can begin to understand how patients may respond to the type of Voice used according to their individual attachment styles. While further research must be conducted to confirm these conjectures, we can theorize patients' preferences based on these concepts. Secure attachment styles will likely be comfortable with the Voice of Medicine, given the individual's propensity to trust. As stated, more complex medical issues demand the Voice of the Lifeworld approach, for the most effective medical interview to take place. Therefore, Voice should adapt in gradation depending on the complexity of the medical issue.

Patients ranging from most secure to least secure may benefit from a communication mix that is primarily Medicine in the former and Lifeworld in the latter. This approach should be tempered depending on the relative complexity and severity of the medical issue. This approach allows for quick dissemination while meeting the relationship needs of patients. Further studies should seek to validate this approach. Overall, understanding a patient's predominant style and matching it with an appropriate mix of Voices is of great importance. This will likely result in a high level of empathy with more effort exerted to connect with some patients, such as those with fearful attachment styles. Effective maneuvering in this realm will allow physicians to break down barriers to relationship-building and trust. This shift will be rewarding for both physician and patient, with more effective interviewing, satisfied patients, better treatment adherence, and ultimately better patient outcomes.

\section{MINIMIZING PHYSICIAN BIAS, POWER CONSTRAINTS, AND PATERNALISM}

In addition to these combined constructs, physicians must consider other factors when interviewing patients. For example, some physicians allow a patient's age to bias what treatment options are offered (41). Similarly, physicians might be biased based on a patient's background. For this reason, Deps \& Charlier (42) identify refugees as a particularly vulnerable group in the healthcare system. Refugees often arrive in host countries having experienced intense mental and physical violence, and present complex health needs. In these unique 
situations, physicians need to extend their greatest efforts to relate to the patient, and the Voice of Medicine will likely be even less understandable to patients due to language and cultural barriers. Understanding is required as patients must be fully informed for the treatment to be considered ethical. Physicians may unintentionally use the Voice of Medicine to obfuscate the facts due to an unconscious bias towards a group of individuals. A US study conducted by Nong et al. (43) found that just over $1 / 5^{\text {th }}$ of participants felt they had been discriminated against in a healthcare setting. Physicians must ensure they are meeting a patient's expectations for communication, as well as recognizing any implicit biases present to mitigate their effects.

Physicians must also realize their position of power in the medical community and the impact it has on patients. Research supports that patients take notice when physicians abuse their power with nurses and will perceive the overall care more poorly when this occurs (44). Specifically in child patients, observing tension between medical professionals will cause intimidation and fear, making the patient less likely to participate in healthcare decisions, inadvertently stifling their right to autonomy (44). Minimizing the patient's role in decision-making also reduces a patient's probability of adhering to a specified treatment plan (45).

When a physician misuses their power to undermine the voice of the patient or unduly influence patient medical decisions, medical paternalism has occurred. Paternalism presumes that physicians always know better than the patient and whatever the physician decides is what is best for the patient. On the spectrum of differing levels of independence, paternalism stands on the opposite side of patient autonomy (46). During the medical interview, physicians who adopt a paternalistic approach are more likely to want short descriptions of physical symptoms that can be transformed into diagnostic categories (47). Unfortunately, the paternalistic demeanor of many physicians is not limited to verbal communication. Whether intentional or not, physicians can still exert control over patient decisions with nonverbal communication, such as body language and facial expressions (48). As with verbal communication, non-verbal factors such as a physician's attitude or tone of voice may also influence patient decisions. When paternalism is verbalized, the Voice of Medicine is likely to be used due to its ability to reduce patient understanding.

\section{CONCLUSION AND RECOMMENDATIONS}

Research within this review of physician-patient communication overwhelmingly supports a patient-centered approach to medical interviewing. This is a notable realization, as the patient-centered philosophy transcends the conventional medical dichotomy between the body and mind, which indicates larger societal transformations in a post-modern era (9). This can be done with moderate changes to a physician's communicative and behavioral approach. To enact such changes, two levels must be considered. First, at the personal level, physicians must grasp this information and reflect upon it to identify their personal responsibility in improving patient care and communication. However, such reflection at a personal level can only be achieved within equitable institutions (40). Thus, at the institutional level, medical education must also adapt. It has been documented that traditional medical education, either at medical school or higher levels, is ineffective at imparting communication competency (49). Through an ethical lens, it is apparent that overuse of the Voice of Medicine can obscure information and subsequently affect patient autonomy. Physicians must be aware of this, as well as power imbalance and implicit bias. Efforts should be directed towards removing barriers to improve communication skills at the curriculum level.

In improving medical education curricula, it remains unclear what the outcome of the reform will be if the language of scientific medicine continues to dominate. There is a need to bring about systemic change in medical school curricula to overcome the communicative gap. This change might require that medical students partake in counseling courses, with the hope of increasing empathy and communication, whilst amplifying the voices of patients. Moreover, future research will build upon the structures lain here. Testing the concept of understanding attachment style and altering Voice may result in patient benefits. Patients could also benefit 
from future studies that determine how to quickly assess a patient's attachment style, as well as what blend of Voices works best depending on patient context. Ideally, this will result in the creation of standard procedures to effectively break down communication barriers and build trust with even the most vulnerable, emotionally guarded patients. After all, medicine cannot fulfill its purpose if it does not fulfill its mission to welcome, offer hospitality, and take care of human distress (40). Physicians must develop a better understanding of their role, and the patient's role, in overcoming barriers to effective communication. This understanding will result in more ethical encounters where information is understood easily. In all of this, physicians must keep patient well-being at the forefront of their practice and fulfill the promises and responsibilities that are assumed when they join the profession. Perhaps the best description of these responsibilities can be found in the 1964 adaptation of the age-old Hippocratic Oath, which physicians traditionally take when they graduate medical school. "There is art to medicine as well as science, and that warmth, sympathy, and understanding may outweigh the surgeon's knife or the chemist's drug... I do not treat a fever chart, a cancerous growth, but a sick human being, whose illness may affect the person's family and economic stability" (50).

\section{REFERENCES}

1. Broyard A. Intoxicated by My Illness. New York: Clarkson Potter; 1992.

2. Garg A, Neuren E, Cha D, Kirby JS, Ingram JR, Jemec GB, et al. Evaluating patients' unmet needs in hidradenitis suppurativa: Results from the Global Survey of Impact and Healthcare Needs (VOICE) Project. J Am Acad Dermatol. 2020; 82(2):366-376.

3. Rocque R, Leanza Y. A systematic review of patients' experiences in communicating with primary care physicians: Intercultural encounters and a balance between vulnerability and integrity. PLoS ONE. 2015; 10(10):e0139577.

4. Feng J, Gabor J, Anoushiravani A, Long W, Vigdorchik J, Meere P, et al. Payer type does not impact patientreported outcomes after primary total knee arthroplasty, Arthroplast Today. 2019; 5(1):113-118.

5. Dambrino RJ, Zuckerman SL, Guidry BS, Domenico HJ, Thompson RC, Galloway MB, et al. Do neurosurgeons receive more patient complaints than other physicians? Describing who is most at risk and how we can improve. J of Neurosurg, 2020; 1(aop):1-8.

6. Williams TP, Jego EH. Terminology, register, and convergence in medical interviews. Medical English Education. 2018; 77.

7. Rey-Bellet S, Dubois J, Vannotti M, Zuercher M, Faouzi M, Devaud K, et al. Agenda Setting During Follow-Up Encounters in a University Primary Care Outpatient Clinic, Health Commun. 2017; 32(6):714-720.

8. Flaherty J. Education and evaluation of interpersonal skills. In: Rezler A, Flaherty J, editors. The interpersonal dimension in medical education. New York: Springer; 1985. p. 101-146.

9. Stewart M, Brown B, Weston W, McWhinney I, McWilliam C, Freeman T. Patient- Centered Medicine: Transforming the Clinical Method. Abingdon: Radcliffe Medical Press; 2003.

10. Dzobo K, Adotey S, Thomford NE, Dzobo W. Integrating artificial and human intelligence: a partnership for responsible innovation in biomedical engineering and medicine. OMICS. 2020; 24(5):247-263.

11. Mishler E. The discourse of medicine: Dialectics of medical interviews. Norwood, NJ: Ablex; 1984.

12. Charon R. The Novelization of the Body, or How Medicine and Stories Need one Another. Narrative. 2011; $19(1): 33-50$.

13. Bute J, Brann M. Tensions and Contradictions in Interns' Communication about Unexpected Pregnancy Loss, Health Commun. 2019. DOI:10.1080/10410236.2019.1570429

14. Adebayo CT. Physician-Patient Interactions in Nigeria: A Critical-Cultural Perspective on the Role of Power. J Intercult Commun Res. 2020; 1-20.

15. Norberg-Boysen G, Nyström M, Christensson L, Herlitz J, Wireklint-Sundström B. Trust in the early chain of healthcare: lifeworld hermeneutics from the patient's perspective. Int J Qual Stud Health Well-being. 2017; 12(1):1356674. 
16. Nilsson K, Bååthe F, Andersson E, Wikström E, Sandoff M. Experiences from implementing value-based healthcare at a Swedish University hospital - a longitudinal interview study. BMC Health Serv. Res. 2017; 17:169.

17. Kirkscey R. Bioethical communication: shared decision-making and relational empathy. J Commun Healthc. 2018; 11(3):164-174.

18. Bommier C, Charlier C, Hervé C. What Symbolic Answers to Death in the Medical World? J International de Bioéthique et D’éthique des Sciences. 2020; 31(1).

19. Silverman D. Communication and Medical Practice: Social relations in the Clinic. London: Sage; 1987.

20. Keshmiri F, Farahmand S, Nejad-Nedaei MD. Exploring the challenges of professional identity formation in clinical education environment: A qualitative study. J Adv Med Educ Prof. 2020; 8(1):42.

21. Barry C, Stevenson F, Britten N, Barber N, Bradley C. Giving voice to the lifeworld. More humane, more effective medical care? A qualitative study of doctor- patient communication in general practice. Social Science and Medicine. 2001; 53(4):487-505.

22. Maunder G, Hunter J. Can patients be 'attached' to healthcare providers? An observational study to measure attachment phenomena in patient-provider relationships. Br Med J. 2016; 6:e011068.

23. Bowlby J. The making and breaking of affectional bonds. I. Etiology and psychopathology in the light of attachment theory. An expanded version of the Fiftieth Maudsley Lecture, delivered before the Royal College of Psychiatrists, 19 November 1976. Br J of Psychiatry, 1977; 130:201- 210

24. Ainsworth S, Bowlby J. An ethological approach to personality development. American Psychologist. 1991; 46:331-341.

25. Belsky J, Nezworski TM. Clinical implications of attachment. Routledge; 2015.

26. Ammaniti M. Implicit knowledge from infancy to the psychotherapeutic relationship: The contribution of Daniel Stern. Psychoanaly Inq. 2018; 38:138-147.

27. Mimura C, Norman J. The relationship between healthcare workers' attachment styles and patient outcomes: a systematic review. Int J for Quality in Health Care. 2018; 30:332- 343.

28. West AL. Associations among attachment style, burnout, and compassion fatigue in health and human service workers: A systematic review. J Hum Behav Soc Environ. 2015; 25(6):571-590.

29. Griffin D, Bartholomew K. The metaphysics of measurement: The case of adult attachment. Advances in Personal Relationships. 1994; 5:17-52.

30. Hunter J, Maunder R, Ravitz P, Soklaridis S. Tell Me What You Understand About Your Patient: Applying Attachment Principles to Medical Education. In: Hunter J, Maunder R, editors. Improving Patient Treatment with Attachment Theory. Cham: Springer; 2016.

31. Posada G, Waters HS. Introduction: The co-construction of mother-child attachment relationships in early childhood. In G. Posada \& H. Waters (Eds.), The mother-child attachment partnership in early childhood: Secure base behavioral and representational processes. Monogr Soc Res Child Dev. 2018; 83(4):331.

32. Klest B, Philippon O. Trust in the medical profession and patient attachment style. Psychology, Health \& Medicine. 2016; 21:7.

33. Simmons BL, Gooty J, Nelson DL, Little LM. Secure attachment: Implications for hope, trust, burnout, and performance. Journal of Org Behav, 2009; 30(2):233-247.

34. Silva G, Swartz M, Molony S. Connecting with chronically ill patients to improve treatment adherence. Nurse Practitioner. 2014; 39:42-48.

35. DeMarco C, Newheiser A. Attachment to groups: Relationships with group esteem, self esteem, and investment in ingroups. Eur J Soc Psychol. 2019; 49(1):63-75.

36. Levy KN, Ellison WD, Scott LN, Bernecker SL. Attachment style. J Clin Psychol. 2011; 67(2):193-203.

37. Tasca G. Attachment and eating disorders: a research update. Curr Opin Psychol. 2018; 25:59-64.

38. Bartholomew K. From childhood to adult relationships: Attachment theory and research. In: Duck S, editor. Learning about Relationships. Thousand Oaks, CA: Sage; 1993. 3-62. 
39. Li S, Galynker II, Briggs J, Duffy M, Frechette-Hagan A, Kim HJ, et al. Attachment style and suicide behaviors in high-risk psychiatric inpatients following hospital discharge: The mediating role of entrapment. Psychiatry Res. 2017; 257:309-314.

40. Hervé C, Duguet AM, Georges C, Golse B, Cordier B, Galichon B, et al. Treating strangeness: medicine and human dignity at the time of COVID-19. Ethics Med Public Health. 2021.

41. Anastasio AT, Niu S, Kim EJ, Rhee JM. Evaluating Single-Surgeon Bias Toward Recommending Corrective Procedures for Cervical Spondylotic Myelopathy Based on Demographic Factors and Comorbidities in a 484-Patient Cohort. Global Spine J. 2021; 11(2):167-171.

42. Deps P, Charlier P. Medical Approach to Refugees: Importance of the Caring Physician. Ann Glob Health. 2020; 86(1).

43. Nong P, Raj M, Creary M, Kardia SL, Platt JE. Patient-Reported Experiences of Discrimination in the US Health Care System. JAMA network open. 2020; 3(12):e2029650-e2029650.

44. Didier A, Gachoud D, von Niederhäusern G, Benaroyo L, Zumstein-Shaha M. Caring moments within an interprofessional healthcare team: Children and adolescent perspectives. Patient Exp J. 2018; 5(2).

45. Khawaja, K. The Mediating Role of Positive and Negative Emotional Attractors Between Psychosocial Correlates of Doctor-Patient Relationship and Treatment of Type II Diabetes [Dissertation]. Cleveland (OH): Case Western Reserve University; 2010.

46. Murgic L, Philip HC, Sovic S, Pavlekovic G. Paternalism and autonomy: views of patients and providers in a transitional (post-communist) country. BMC Med Ethics. 2015; 16(65).

47. Roeland E, Cain J, Onderdonk C, Kerr K, Mitchell W, Thornberry K. When open-ended questions don't work: the role of palliative paternalism in difficult medical decisions. J Palliat Med. 2014; 17(4):415-420.

48. Bommier C, Mamzer-Bruneel M, Desmarchelier D, Hervé C. How nonverbal communication shapes doctorpatient relationship: From paternalism to the ethics of care in oncology. J International de Nioéthique. 2013; 4(24):137-158.

49. Sanson-Fisher R, Hobden B, Waller A, Dodd N, Boyd L. Methodological quality of teaching communication skills to undergraduate medical students: a mapping review. BMC Med Educ. 2018; 18:151.

50. Lasagna L. Modern Hippocratic Oath. Boston, MA. 1964. 